\title{
Prevalence of Circadian Blood Pressure Patterns and Factors Associated with Non-Dipping among Black Patients with Untreated and Treated Hypertension: A Cross-Sectional Study
}

\author{
T. S. Mvunzi', Y. Lubenga1, F. B. Lepira ${ }^{2 *}$, J. R. Makulo², A. Nkodila ${ }^{3}$, D. K. Kuntonda ${ }^{1}$, \\ Y. Samafundu1, Y. M. Nlandu' ${ }^{2}$, Y. M. Engole², B. P. Kianu1, F. Kintoki', D. Mupepe1, \\ N. Buila1, R. M. Kongo4, E. V. Kintoki1 \\ ${ }^{1}$ Division of Cardiology, University of Kinshasa Hospital, Kinshasa, Congo \\ ${ }^{2}$ Division of nephrology, Department of Internal Medicine, University of Kinshasa Hospital, Kinshasa, Congo \\ ${ }^{3}$ Centre medical cite des aveugles, University of Kinshasa Hospital, Kinshasa, Congo \\ ${ }^{4}$ Clinique ngaliema, University of Kinshasa Hospital, Kinshasa, Congo \\ Email: *lepslepira@yahoo.fr
}

How to cite this paper: Mvunzi, T.S., Lubenga, Y., Lepira, F.B., Makulo, J.R., Nkodila, A., Kuntonda, D.K., Samafundu, Y., Nlandu, Y.M., Engole, Y.M., Kianu, B.P., Kintoki, F., Mupepe, D., Buila, N., Kongo, R.M. and Kintoki, E.V. (2017) Prevalence of Circadian Blood Pressure Patterns and Factors Associated with Non-Dipping among Black Patients with Untreated and Treated Hypertension: A Cross-Sectional Study. World Journal of Cardiovascular Diseases, 7, 399-412. https://doi.org/10.4236/wjcd.2017.711038

Received: September 15, 2018 Accepted: November 21, 2017 Published: November 24, 2017

Copyright $\odot 2017$ by authors and Scientific Research Publishing Inc. This work is licensed under the Creative Commons Attribution International License (CC BY 4.0).

http://creativecommons.org/licenses/by/4.0/ (c) (i) Open Access

\begin{abstract}
Objective: To determine the prevalence of circadian BP patterns and to assess factors associated with the non-dipping pattern in untreated and treated hypertensive patients, studied separately. Methods: Clinical data and ABPM were obtained from 52 untreated and 168 treated hypertensive patients referred for ABPM to Monkole Hospital in Kinshasa. Twenty-four ABPM was performed using an oscillometric device. Non-dipping pattern encompasses non-dipping (nocturnal systolic BP dip less than 10\% of daytime systolic BP) and reverse dipping (mean night SBP higher than the day SBP). Results: the prevalence of non-dipping pattern was 75\% (63.5\% non-dipping and $11.5 \%$ reverse dipping) and $70 \%$ (60.1\% non-dipping and $10.1 \%$ reverse dipping) in untreated and treated hypertensive patients, respectively. Advanced age (adjusted OR 1.80; 95\%CI 1.96 - 3.38; $p=0.015$ ), female sex (adjusted OR 2.28; 95\%CI $1.19-4.36 ; p=0.013$ ), diabetes (adjusted OR 5.06; 95\%CI $1.38-6.95 ; p$ $=0.014$ ), reduced kidney function (adjusted OR 3.10; 95\%CI $1.50-6.43 ; p=$ 0.018 ), inflammation (adjusted OR 2.65; 95\%CI $1.76-6.48 ; p=0.031$ ), LVH (adjusted OR 4.45; 95\%CI $1.78-7.67 ; p=0.024$ ) and antihypertensive therapy (adjusted OR 0.19; 95\%CI $0.12-0.64 ; p=0.018$ ) emerged as the main independent factors significantly associated with the non-dipping pattern in the study population. Conclusion: the non-dipping pattern was a common find-
\end{abstract}


ing in studied patients and associated with traditional and emerging risk factors suggesting that this abnormal pattern could be a marker of high cardiovascular risk.

\section{Keywords}

Non-Dipping, Prevalence, Risk Factors, Hypertension, Black Africans

\section{Introduction}

Accurate assessment of blood pressure (BP) is essential to the diagnosis, prognosis and treatment of hypertension [1]. In this regard, ambulatory BP monitoring (ABPM) has become a useful tool for therapeutic decision making in hypertensive patients and other subjects at high risk for cardiovascular disease (CVD) [1]. In both untreated and treated hypertensive patients, ABPM offers more accurate prognostic information on cardiovascular outcomes than office readings [1]. In addition to mean 24-hour BP, ABPM provides also useful information on the variation in the day to night BP pattern known as dipping status, a powerful predictor of both target organ damage and cardiovascular events [1]. Indeed, subjects with a blunted nocturnal BP decrease (<10\%) known as "non-dippers" or even those with an increased BP during the night known as "reverse dippers" have been reported to be at an increased risk of CV events and mortality [1] [2]. Therefore, assessing BP dipping status in untreated and treated hypertensive patients bears an important prognostic and therapeutic value [1] [2].

In the Democratic Republic of the Congo (DRC), a post-conflict country confronted with multiple social and economic challenges and with limited resources, hypertension [3] [4] [5] has become a major public health problem associated with a high morbidity and mortality mainly due to poor BP control [6] [7] [8] [9]. Therefore, the accurate identification of true hypertension in newly diagnosed patients and its control in those already on treatment as well as the assessment of circadian BP patterns are of prognostic and therapeutic importance, especially in resource-poor settings. Despite its well-known limitations, the diagnosis and management of hypertension relies still on the office blood pressure. Therefore, we took advantage of the availability of ABPM devices at Monkole Hospital, a secondary level hospital, to assess the BP profile of hypertensive patients referred for 24-hour ABPM. The objective of the present study was to determine the prevalence of circadian BP patterns and identify factors associated with the non-dipping status in untreated and treated hypertensive patients studied separately.

\section{Patients and Methods}

We retrospectively review files of patients ( $\geq 18$ years old) who had undergone ABPM from July 2014 to December 2015. Variables collected for each patient 
based on interviews, physical examination at the time of the first visit and on data drawn from clinical records were sex, age, educational level, medical history hypertension, diabetes, smoking and alcohol intake, echocardiographic data (left ventricular hypertrophy/LVH, Ejection fraction/EF, Shortening fraction/SF), height and weight for calculation of body mass index (BMI), office systolic and diastolic BP, drug history, mean day time systolic (diastolic) ambulatory BP, mean night time systolic (diastolic) ambulatory BP. Those who smoked at least one cigarette per day at the time of consultation were classified as active smokers. The drug history included the number, name and class of the antihypertensive medications.

Seated office BP (OBP) measurement was taken on the left arm by a trained nurse after 5 minutes of rest, using an automated electronic sphygmomanometer (OMRON M3 HEM-7200-E Omron Matsusaka Co. Ltd., Kyoto, Japan). Three consecutive BP measurements were taken with one minute interval between readings and the average of the 3 values was considered as the office BP. $24 \mathrm{~h}$-ABPM was performed using a commercially available system (Space Labs 90207 system). A typical weekday was chosen for different patients and normal daily activities were allowed. BP was recorded during the day for every 15 minutes (from 07:00 to 21:00) and every 30 minutes during the night (from 21:00 to 07:00). The mean systolic (SBP) and diastolic BP (DBP) was calculated for daytime and night time within 24 hrs of recording. ABPM records were considered valid only if the number of BP recordings were at least $70 \%$ of the expected readings assessed as valid by the software analysis; otherwise patients underwent a second recording. A normal dipping pattern (dipper) was diagnosed when the reduction in the average SBP during the night period was $>10 \%$ of mean SBP during the day. When this proportion was $>20 \%$, the patient was classified as an extreme dipper. An abnormal dipper pattern (non-dipper) was diagnosed when the night average $\mathrm{SBP}$ reduction was $<10 \%$ with respect to day values. When the mean night SBP was higher than the day one, the patient was classified as a riser or reverse dipper. Dipper and extreme dipper defined "dipper" pattern whereas non dipper and reverse dipper were considered "non-dipping pattern" for analysis [1].

Statistical analyses were performed using the Statistical Package for Social Sciences (SSPS Inc., Chicago, Illinois, USA) version 17.0 software. Results are summarized as counts and percentages for qualitative variables and as mean \pm standard deviation (SD) for quantitative variables. Comparisons of means and proportions were done using Student t-test and chi-square test, respectively. Independent factors associated with non-dipping pattern were assessed using multivariate logistic regression analysis. A $p$-value $<0.05$ defined the level of statistical significance.

\section{Results}

Table 1 gives clinical characteristics of the study population as a whole and according to antihypertensive therapy status. Two hundred twenty patients (Mean 
Table 1. General characteristics of the study population as a whole and according to antihypertensive therapy.

\begin{tabular}{|c|c|c|c|c|c|}
\hline Variable & $\mathrm{N}$ & All & $\begin{array}{l}\text { Untreated } \\
(\mathrm{n}=52)\end{array}$ & $\begin{array}{l}\text { Treated } \\
(\mathrm{n}=168)\end{array}$ & $p$ \\
\hline Age, year & 220 & $53.6 \pm 11.6$ & $48.9 \pm 12.2$ & $55.1 \pm 11.6$ & 0.001 \\
\hline Gender, n (\%) & 220 & & & & 0.121 \\
\hline M & & $115(52.3)$ & $23(44.2)$ & $92(54.8)$ & \\
\hline $\mathrm{F}$ & & $105(47.7)$ & $29(55.8)$ & $76(45.2)$ & \\
\hline Alcohol, n (\%) & 220 & $80(36.5)$ & $22(43.1$ & $58(34.5)$ & 0.170 \\
\hline Smoking, n (\%) & 220 & $28(12.8)$ & $6(11.8)$ & $22(13.1)$ & 0.509 \\
\hline Diabetes, n (\%) & 220 & $67(30.5)$ & $13(25.0)$ & $54(32.1)$ & 0.212 \\
\hline BMI, $\mathrm{Kg} / \mathrm{m}^{2}$ & 220 & $28.9 \pm 4.6$ & $28.8 \pm 5.0$ & $28.9 \pm 4.5$ & 0.904 \\
\hline Obesity, n (\%) & 220 & $81(36.8)$ & $17(32.7)$ & $64(38.1)$ & 0.296 \\
\hline Dyslipidemia, n (\%) & 208 & $109(49.5)$ & $27(51.9)$ & $82(48.8)$ & 0.408 \\
\hline LVH, n (\%) & 214 & $88(41.1)$ & $17(34.7)$ & $71(43.0)$ & 0.191 \\
\hline Hypertensive retinopathy, n (\%) & 207 & $77(37.2)$ & $16(34.0)$ & $61(38.1)$ & 0.371 \\
\hline Office SBP, mm Hg & 220 & $144.0 \pm 20.4$ & $144.6 \pm 20.3$ & $143.8 \pm 12.9$ & 0.814 \\
\hline Office DBP, mmHg & 220 & $88.8 \pm 13.0$ & $89.3 \pm 13.2$ & $88.7 \pm 13.0$ & 0.762 \\
\hline 24H ABPM SBP, mm Hg & 220 & $133.0 \pm 12.9$ & $132.3 \pm 10.9$ & $133.2 \pm 13.5$ & 0.647 \\
\hline 24H ABPM DBP, mm Hg & 220 & $86.8 \pm 10.3$ & $85.8 \pm 8.4$ & $87.1 \pm 10.9$ & 0.425 \\
\hline $\mathrm{Hb}, \mathrm{g} / \mathrm{dl}$ & 170 & $12.5 \pm 1.6$ & $12.6 \pm 1.4$ & $12.4 \pm 1.7$ & 0.414 \\
\hline Anemia, n (\%) & 170 & $24(14.1)$ & $4(8.2)$ & $20(16.5)$ & 0.117 \\
\hline $\mathrm{HbAlc}, \%$ & 41 & $7.1 \pm 1.8$ & $7.2 \pm 2.6$ & $7.1 \pm 1.6$ & 0.927 \\
\hline $\mathrm{CRP}, \mathrm{mg} / \mathrm{l}$ & 213 & $5.0 \pm 1.3$ & $5.1 \pm 1.2$ & $5.0 \pm 1.5$ & 0.948 \\
\hline CRP > 3 mg/l, n (\%) & 213 & $121(55.0)$ & $38(73.1)$ & $83(49.4)$ & 0.002 \\
\hline $\mathrm{TC}, \mathrm{mg} / \mathrm{dl}$ & 208 & $203.5 \pm 41.9$ & $205.0 \pm 39.5$ & $203.1 \pm 42.8$ & 0.774 \\
\hline LDL-c, mg/dl & 208 & $130.7 \pm 38.8$ & $130.7 \pm 37.5$ & $130.6 \pm 39.4$ & 0.986 \\
\hline HDL-c, mg/dl & 208 & $50.3 \pm 14.7$ & $53.9 \pm 14.8$ & $49.2 \pm 14.5$ & 0.049 \\
\hline $\mathrm{TG}, \mathrm{mg} / \mathrm{dl}$ & 208 & $112.6 \pm 37.5$ & $105.3 \pm 37.8$ & $114.9 \pm 37.2$ & 0.111 \\
\hline FPG, mg/dl & 163 & $99.4 \pm 31.2$ & $92.3 \pm 22.5$ & $102.3 \pm 33.8$ & 0.064 \\
\hline Creatinine, $\mathrm{mg} / \mathrm{dl}$ & 214 & $1.11 \pm 0.8$ & $1.15 \pm 0.44$ & $1.10 \pm 0.53$ & 0.693 \\
\hline eGFR, $\mathrm{ml} / \mathrm{min} / 1.73 \mathrm{~m}^{2}$ & 214 & $95.3 \pm 36.8$ & $97.9 \pm 30.9$ & $94.5 \pm 38.5$ & 0.568 \\
\hline $\mathrm{eGFR}<60 \mathrm{ml} / \mathrm{min} / 1.73 \mathrm{~m}^{2}$ & 214 & $36(16.8)$ & $5(10.0)$ & $31(18.9)$ & 0.101 \\
\hline Proteinuria, n (\%) & 210 & $74(35.0)$ & $16(34.0)$ & $58(35.6)$ & 0.495 \\
\hline
\end{tabular}

Data are expressed as mean \pm standard deviation (n) absolute and relative frequency (in percent). Abbreviations: M, male; F, female; BMI, body mass index; LVH, left ventricular hypertrophy; Hb, hemoglobin; HbAlc, glycated hemoglobin; CRP, C-reactive protein; TC, total cholesterol; LDL-c, low-density lipoprotein-cholesterol; HDL-c, high-density lipoprotein-cholesterol; TG, triglycerides; FPG, fasting plasma glucose; eGFR, estimated glomerular filtration rate. 
age $53.6 \pm 11.6$ years; $52.3 \%$ men) were included in the present study. Fifty two of them (52.2\% men; mean age $48.9 \pm 12.2$ years) were not yet receiving antihypertensive therapy whereas 168 patients (52.2\%) men; mean age $55.1 \pm 11.2$ years) were already on antihypertensive therapy. Monotherapy with mainly calcium channel blockers (CCB), bitherpay with mainly $\mathrm{CCB}+$ angiotensin converting enzyme inhibitors (ACEIs) and tritherpay with mainly CCB + ACEI + thiazide were present in $36 \%, 36 \%$ and $18.5 \%$ of patients, respectively. Office and $24-\mathrm{H}$ ambulatory BP were in average $144.0 \pm 20.4 / 88.8 \pm 13.0 \mathrm{mmHg}$ et $133.0 \pm$ $12.9 / 86.8 \pm 10.3 \mathrm{mmHg}$, respectively; mean BMI was $28.9 \pm 4.6 \mathrm{Kg} / \mathrm{m}^{2}$. Main cardiovascular risk factors were elevated CRP (55\%), dyslipidemia (49.5\%), advanced age (48.2\%), obesity (36.8\%), proteinuria $(35.2 \%)$ and diabetes $(30.5 \%)$. Treated patients were in average significantly older $(55.1 \pm 11.6$ vs. $48.9 \pm 12.2$ years; $p=0.001)$ than untreated ones; they also had significantly lower HDL-c levels $(49.2 \pm 14.5$ vs. $53.9 \pm 14.8 \mathrm{mg} / \mathrm{dl} ; p=0.049)$ and proportion (49.4 vs. $73.1 \% ; p=0.002$ ) of subjects with increased CRP levels.

Prevalence of different circadian BP patterns are summarized in Figure 1. In untreated patients, dipper, non-dipper and reverse dipper patterns were observed in $25 \%, 63.5 \%$ and $11.5 \%$ of patients, respectively. The figure in treated patients was $29.8 \%, 60.1 \%$ and $10.1 \%$ for dipper, non-dipper and reverse dipper patterns, respectively. Extreme dipper pattern was not observed in both untreated and treated patients. Therefore, the prevalence of dipping (dippers + extreme dippers) and non-dipping (non-dippers + reverse dippers) patterns was $25 \%$ and $75 \%$ in untreated patients and $29.8 \%$ and $70.2 \%$ in those on antihypertensive therapy.

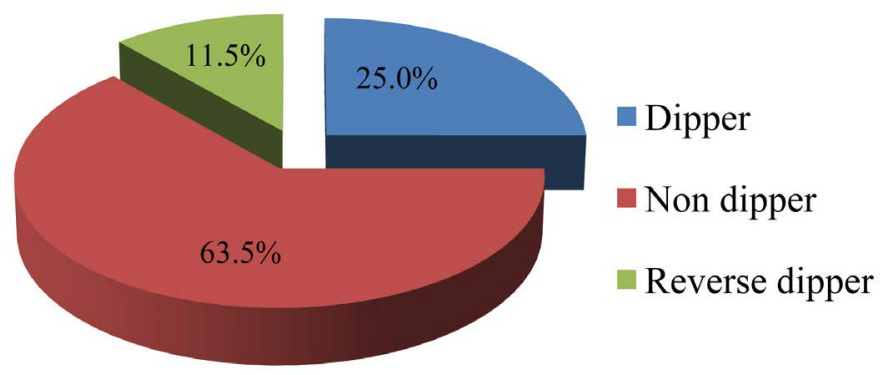

(a)

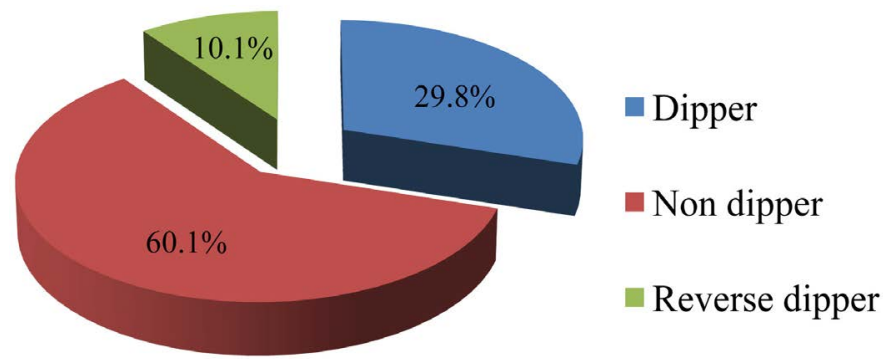

(b)

Figure 1. Prevalence of circadian blood pressure patterns in untreated $(n=52)(a)$ and treated $(n=168)(b)$ hypertensive patients. 
Clinical characteristics of untreated and treated patients according to dipping status are depicted in Table 2. Non-dipper and reverse dipper untreated patients had a significantly higher proportion (80\% for reverse dipper, $35.5 \%$ for non-dipper vs. $15.4 \%$ for dipper patients; $p=0.036$ ) of subjects with LVH. They tended to be older and to have a lower proportion of subjects consuming alcohol; however, the difference was not statistically significant. Non-dipper patients had in addition a significantly higher proportion $(48.5 \%$ vs. $7.7 \%$; $p=0.003)$ of obese than non-dipper ones. Like untreated patients, non-dipper and reverse dipper patients had a significantly higher proportion $(43.8 \%$ for reverse dipper, $51.5 \%$ for non-dipper vs. $26.0 \%$ for dipper patients; $p=0.011$ ) of subjects with LVH. They had in addition a significantly higher proportion $(62.5 \%$ for reverse dipper, $37.5 \%$ for non-dipper vs. $31.3 \%$ for dipper patients; $p=0.031$ ) of subjects with hypertensive retinopathy and were older $(55.2 \pm 13.9$ years for reverse dipper, $56.6 \pm 10.5$ years for non-dipper vs. $51.9 \pm 10.5$ years for dipper patients; $p=$ 0.046) than dipper ones.

Table 2. Clinical characteristics of the study population according to antihypertensive therapy and dipping status.

\begin{tabular}{|c|c|c|c|c|c|c|c|c|}
\hline \multirow[b]{2}{*}{ Variable } & \multicolumn{4}{|c|}{ Untreated $(\mathrm{n}=52)$} & \multicolumn{4}{|c|}{ Treated $(n=168)$} \\
\hline & $\begin{array}{l}\text { Dipper } \\
\mathrm{n}=13\end{array}$ & $\begin{array}{l}\text { Non-dipper } \\
\quad \mathrm{n}=13\end{array}$ & $\begin{array}{c}\text { Reverse } \\
\text { dipper } \\
n=6\end{array}$ & $p$ & $\begin{array}{l}\text { Dipper } \\
\mathrm{n}=50\end{array}$ & $\begin{array}{c}\text { Non-dipper } \\
\mathrm{n}=101\end{array}$ & $\begin{array}{l}\text { Reverse } \\
\text { dipper } \\
\mathrm{n}=17\end{array}$ & $p$ \\
\hline Age, years & $44 \pm 9.2$ & $48.8 \pm 12.4$ & $58.8 \pm 12.2$ & 0.052 & $51.9 \pm 10.5$ & $56.6 \pm 10.5$ & $55.2 \pm 13.9$ & 0.046 \\
\hline Gender, n (\%) & & & & 0.386 & & & & 0.110 \\
\hline M & $4(30.8)$ & $15(45.5)$ & $4(66.7)$ & & $32(64.0)$ & $54(53.5)$ & $6(35.3)$ & \\
\hline $\mathrm{F}$ & $9(69.2)$ & $18(54.5)$ & $2(33.3)$ & & $18(36.0)$ & $47(46.8)$ & $11(64.7)$ & \\
\hline Alcohol, n (\%) & $9(69.2)$ & $10(31.8)$ & $3(50.0)$ & 0.066 & $15(30.0)$ & $39(38.6)$ & $4(23.5)$ & 0.352 \\
\hline Smoking, n (\%) & $2(15.4)$ & $3(9.4)$ & $1(16.4)$ & 0.543 & $5(10.0)$ & $15(14.9)$ & $2(11.8)$ & 0.750 \\
\hline Diabetes, n (\%) & $2(15.4)$ & $10(30.3)$ & $1(16.7)$ & 0.563 & $17(34.0)$ & $28(27.7)$ & $9(52.9)$ & 0.112 \\
\hline BMI, $\mathrm{Kg} / \mathrm{m}^{2}$ & $26.7 \pm 5.2$ & $29.8 \pm 5.1$ & $27.6 \pm 2.6$ & 0.138 & $28.6 \pm 3.7$ & $28.7 \pm 4.6$ & $30.7 \pm 5.4$ & 0.221 \\
\hline Obesity, n (\%) & $1(7.7)$ & $16(48.5)$ & $0(0.0)$ & 0.003 & $2(4.0)$ & $32(31.7)$ & $10(58.8)$ & 0.055 \\
\hline Dyslipidemia, n (\%) & $6(44.2)$ & $19(57.6)$ & $2(33.3)$ & 0.114 & $20(40.0)$ & $52(51.5)$ & $10(58.8)$ & 0.286 \\
\hline \multicolumn{9}{|l|}{ Daytime BP } \\
\hline SBP (mmHg) & $130.1 \pm 8.8$ & $135.5 \pm 11.1$ & $130.7 \pm 7.1$ & 0.219 & $133.5 \pm 7.7$ & $134.5 \pm 14.3$ & $138.6 \pm 17.0$ & 0.379 \\
\hline DBP (mmHg) & $86.8 \pm 7.1$ & $89.5 \pm 8.8$ & $81.8 \pm 5.2$ & 0.096 & $89.6 \pm 8.7$ & $88.5 \pm 11.3$ & $85.1 \pm 13.1$ & 0.853 \\
\hline \multicolumn{9}{|l|}{ Nighttime BP } \\
\hline SBP (mmHg) & $113.9 \pm 8.3$ & $130.6 \pm 14.0$ & $132.8 \pm 17.7$ & 0.001 & $116.4 \pm 7.5$ & $130.7 \pm 16.2$ & $146.9 \pm 18.6$ & $<0.001$ \\
\hline $\mathrm{DBP}(\mathrm{mmHg})$ & $71.8 \pm 6.4$ & $81.0 \pm 9.1$ & $70.3 \pm 26.9$ & 0.022 & $73.8 \pm 7.6$ & $80.7 \pm 11.2$ & $90.4 \pm 13.5$ & $<0.001$ \\
\hline \multicolumn{9}{|l|}{$24 \mathrm{~h} \mathrm{BP}$} \\
\hline $\mathrm{SBP}(\mathrm{mmHg})$ & $126.5 \pm 8.7$ & $134.5 \pm 11.7$ & $132.5 \pm 6.8$ & 0.081 & $129.9 \pm 8.0$ & $133.7 \pm 14.5$ & $140.5 \pm 17.3$ & 0.016 \\
\hline DBP (mmHg) & $83.2 \pm 7.0$ & $87.6 \pm 8.9$ & $81.5 \pm 5.7$ & 0.115 & $86.0 \pm 8.5$ & $87.3 \pm 11.5$ & $89.3 \pm 12.9$ & 0.533 \\
\hline LVH, n (\%) & $2(15.4)$ & $11(35.5)$ & $4(80)$ & 0.036 & $13(26.0)$ & $51(51.5)$ & $7(43.8)$ & 0.011 \\
\hline Hypertensive retinopathy, $\mathrm{n}(\%)$ & $2(15.4)$ & $11(35.5)$ & $3(50)$ & 0.288 & $15(31.3)$ & $36(37.5)$ & $10(62.5)$ & 0.031 \\
\hline
\end{tabular}

Data are expressed as mean \pm standard deviation, absolute frequency $(\mathrm{n})$ and relative frequency (in percent). Abbreviations: $\mathrm{BMI}=$ body mass index; WC $=$ waist circumference; $\mathrm{LVH}=$ left ventricular hypertrophy. 
Biological characteristics of the study population according to antihypertensive therapy and circadian BP patterns are depicted in Table 3. Non-dipper and reverse dipper untreated patients had in average significantly higher $(12.5 \pm 1.6$ $\mathrm{mg} / \mathrm{dl}$ for reverse dipper, $6.5 \% \pm 1.2 \%$ for non-dipper vs. $5.1 \% \pm 1.1 \%$ for dipper patients; $p=0.023$ ) HbA1c levels than dipper ones. They tended to have lower eGFR levels than those with dipper pattern; however, the difference was not statistically significant. Non-dipper and reverse dipper treated patients had in average significantly higher TG $(130.4 \pm 39.9 \mathrm{mg} / \mathrm{dl}$ for reverse dipper, $119.4 \% \pm$ $36.6 \%$ for non-dipper vs. $105.3 \% \pm 32.2 \%$ for dipper patients; $p=0.021$ ) levels and lower eGFR $\left(91.1 \pm 48.9 \mathrm{ml} / \mathrm{min} / 1.73 \mathrm{~m}^{2}\right.$ for reverse dipper, $86.9 \pm 36.8$ $\mathrm{ml} / \mathrm{min} / 1.73 \mathrm{~m}^{2}$ for non-dipper vs. $110.9 \pm 33.3 \mathrm{ml} / \mathrm{min} / 1.73 \mathrm{~m}^{2} ; p=0.001$ ) for dipper pattern; $p=0.023$ ) than those with dipper pattern.

Table 4 summarizes factors associated with the non-dipping pattern in the study population as a whole using logistic regression analysis. In univariate analysis, advanced age, female sex, diabetes, reduced kidney function (eGFR $<60$ $\mathrm{ml} / \mathrm{min} / 1.73 \mathrm{~m}^{2}$ ), increased CRP levels (inflammation), LVH, antihypertensive therapy, obesity and dyslipidemia were significantly associated with the non-dipping pattern. In multivariate analysis, the strength of the associations observed in univariate analysis only persisted for advanced age (adjusted OR 1.80; 95\%CI 1.96 - 3.38; $p=0.015$ ), female sex (adjusted OR 2.28; 95\%CI $1.19-4.36 ; p=0.013$ ), diabetes (adjusted OR 5.06; 95\%CI $1.38-6.95 ; p=0.014$ ), reduced kidney func-

Table 3. Biological characteristics of the study population according to antihypertensive therapy and dipping status.

\begin{tabular}{|c|c|c|c|c|c|c|c|c|}
\hline \multirow[b]{2}{*}{ Variable } & \multicolumn{4}{|c|}{ Untreated $(\mathrm{n}=52)$} & \multicolumn{4}{|c|}{ Treated $(\mathrm{n}=168)$} \\
\hline & $\begin{array}{l}\text { Dipper } \\
\mathrm{n}=13\end{array}$ & $\begin{array}{c}\text { Non-dipper } \\
n=13\end{array}$ & $\begin{array}{c}\text { Reverse } \\
\text { dipper } \\
n=6\end{array}$ & $p$ & $\begin{array}{c}\text { Dipper } \\
\mathrm{n}=50\end{array}$ & $\begin{array}{c}\text { Non-dipper } \\
\mathrm{n}=101\end{array}$ & $\begin{array}{c}\text { Reverse } \\
\text { dipper } \\
\mathrm{n}=17\end{array}$ & $p$ \\
\hline $\mathrm{Hb}, \mathrm{g} / \mathrm{dl}$ & $12.7 \pm 1.1$ & $12.7 \pm 1.5$ & $11.9 \pm 1.1$ & 0.356 & $12.8 \pm 1.8$ & $12.3 \pm 1.5$ & $12.2 \pm 2.1$ & 0.322 \\
\hline Anemia, n (\%) & $0(0.0)$ & $3(9.70)$ & $1(16.7)$ & 0.294 & $4(11.1)$ & $11(15.5)$ & $5(35.7)$ & 0.015 \\
\hline $\mathrm{HbAlc,} \%$ & $5.1 \pm 1.1$ & $6.5 \pm 1.2$ & $12.5 \pm 1.6$ & 0.023 & $7.3 \pm 1.5$ & $7.5 \pm 1.7$ & $5.9 \pm 1.1$ & 0.082 \\
\hline $\mathrm{CRP}, \mathrm{mg} / \mathrm{l}$ & $4.5 \pm 2.1$ & $5.5 \pm 2.6$ & $3.8 \pm 1.2$ & 0.399 & $3.3 \pm 1.3$ & $5.7 \pm 1.4$ & $6.0 \pm 1.7$ & 0.154 \\
\hline $\mathrm{CRP}>3 \mathrm{mg} / \mathrm{l}, \mathrm{n}(\%)$ & $9(69.2)$ & $25(75.8)$ & $4(66.7)$ & 0.723 & $14(28.0)$ & $59(58.4)$ & $10(58.8)$ & 0.001 \\
\hline $\mathrm{TC}, \mathrm{mg} / \mathrm{dl}$ & $195.6 \pm 33.5$ & $211.1 \pm 42.6$ & $187.5 \pm 23.1$ & 0.301 & $195.1 \pm 35.4$ & $206.5 \pm 43.2$ & $207.8 \pm 58.2$ & 0.293 \\
\hline LDL-c, mg/dl & $117.7 \pm 25.5$ & $137.6 \pm 41.6$ & $116.9 \pm 19.8$ & 0.202 & $122.2 \pm 30.4$ & $134.8 \pm 41.7$ & $132.4 \pm 47.6$ & 0.192 \\
\hline HDL-c, mg/dl & $57.5 \pm 15.3$ & $53.3 \pm 15.1$ & $48.7 \pm 11.6$ & 0.509 & $51.4 \pm 15.7$ & $47.8 \pm 13.3$ & $50.8 \pm 17.2$ & 0.325 \\
\hline $\mathrm{TG}, \mathrm{mg} / \mathrm{dl}$ & $109.8 \pm 59.7$ & $101.1 \pm 42.6$ & $109.5 \pm 41.5$ & 0.682 & $105.3 \pm 32.2$ & $119.4 \pm 36.6$ & $130.4 \pm 39.9$ & 0.021 \\
\hline FPG, mg/dl & $84.9 \pm 11.9$ & $93.2 \pm 17.5$ & $101.4 \pm 48.9$ & 0.340 & $104.3 \pm 39.9$ & $98.4 \pm 29.1$ & $116.7 \pm 37.6$ & 0.167 \\
\hline Creatinine, mg/dl & $0.82 \pm 0.23$ & $1.30 \pm 0.70$ & $1.00 \pm 0.20$ & 0.564 & $0.90 \pm 0.20$ & $1.20 \pm 0.60$ & $1.10 \pm 0.50$ & 0.005 \\
\hline MDRD-eGFR, $\mathrm{ml} / \mathrm{min} / 1.73 \mathrm{~m}^{2}$ & $116.1 \pm 31.5$ & $91.1 \pm 30.1$ & $98.3 \pm 21.8$ & 0.054 & $110.9 \pm 33.3$ & $86.9 \pm 36.8$ & $91.1 \pm 48.9$ & 0.001 \\
\hline Proteinuria, n (\%) & $3(27.3)$ & $11(36.7)$ & $2(33.3)$ & 0.133 & $14(29.2)$ & $37(37.8)$ & $7(41.2)$ & 0.510 \\
\hline
\end{tabular}

Data are expressed as mean \pm standard deviation, absolute $(\mathrm{n})$ and relative (in percent) frequency. Hb: hemoglobin; HbAlc, glycated hemoglobin; CRP: c-reactive protein; TC: total cholesterol; LDL-c: low-density lipoprotein-cholesterol; HDL-c: high-density lipoprotein-cholesterol; TG: triglycerides; FPG: fasting plasma glucose; MDRD: modification of diet in renal disease; eGFR: estimated glomerular filtration rate. 
Table 4. Univariate and multivariate factors associated with non-dipping (non-dipper + reverse dipper) pattern in the study population as a whole in logistic regression analysis.

\begin{tabular}{ccccc}
\hline Variable & $p$ & OR (IC95\%) & $p$ & aOR (95\%CI) \\
\hline Advanced age (yes vs. no) & 0.023 & $2.42(1.79-4.53)$ & 0.015 & $1.80(1.96-3.38)$ \\
sex (Female vs. male) & 0.037 & $1.81(1.04-3.13)$ & 0.013 & $2.28(1.19-4.36)$ \\
Diabetes (yes vs. no) & 0.007 & $3.26(1.41-6.29)$ & 0.014 & $5.06(1.38-6.95)$ \\
eGFR $<60 \mathrm{ml} / \mathrm{min} / 1.73 \mathrm{~m}^{2}$ (yes vs. no) & 0.024 & $1.95(1.09-5.85)$ & 0.018 & $3.10(1.50-6.43)$ \\
CRP > 3 mg/l (yes vs. no) & 0.006 & $5.50(1.73-7.24)$ & 0.031 & $2.65(1.76-6.48)$ \\
LVH (yes vs. no) & 0.015 & $3.20(1.69-6.11)$ & 0.024 & $4.45(1.78-7.67)$ \\
Antihypertensive therapy (yes vs. no) & 0.012 & $0.28(0.17-0.64)$ & 0.002 & $0.16(0.12-0.64)$ \\
Obesity (yes vs. no) & 0.034 & $1.77(1.13-2.33)$ & 0.381 & $1.34(0.69-2.58)$ \\
Dyslipidemia (yes vs. no) & 0.020 & $3.50(1.80-7.82)$ & 0.708 & $1.12(0.61-2.05)$ \\
& - & - & 0.005 & 1.402 \\
\hline
\end{tabular}

${ }^{*}$ Age $>45$ years (males) and $>55$ years (females). Abbreviations: aOR, adjusted odds ratio; eGFR, estimated glomerular filtration rate; CRP, c-reactive protein; LVH, left ventricular hypertrophy.

tion (adjusted OR 3.10; 95\%CI $1.50-6.43 ; p=0.018$ ), inflammation (adjusted OR 2.65; 95\%CI 1.76 - 6.48; $p=0.031$ ), LVH (adjusted OR 4.45; 95\%CI 1.78 - 7.67; $p=0.024$ ) and antihypertensive therapy (adjusted OR 0.16 ; $95 \% \mathrm{CI} 0.12-0.64$; $p=0.002)$.

\section{Discussion}

The present study carried out in both untreated and treated hypertensive patients showed that 7 in 10 patients presented with a non-dipping circadian BP pattern. Traditional (advanced age, female sex, diabetes) and emerging (inflammation) as well as target organ damage (LVH and reduced kidney function) and antihypertensive therapy were significantly associated with the non-dipping pattern in the study population.

Whatever the antihypertensive therapy status, 7 in 10 patients had a non-dipping circadian BP pattern. The frequency of the non-dipping pattern found among untreated patients in the present study is higher than that of about $25 \%$ usually reported in the literature [10] and could be explained by the clustering of multiple risk factors associated with this abnormal circadian BP pattern. In treated patients, the frequency of non-dipping pattern observed in the present study is higher than that of $43 \%, 53 \%$ and $61 \%$ found Ikama et al. [11] in Brazzaville, Congo and Uys et al. [12] in the North-West province, South Africa, respectively. It is, however, similar to that of $72.2 \%$ reported by Ivy et al. [13] in 79 patients from South Africa of whom $26.6 \%$ were receiving antihypertensive medication. Apart from the clustering of multiple risk factors, the disparity observed in the frequency of non-dipping pattern in different studies could be explained by the antihypertensive regimen used in each study. Indeed, in contrast to our study where most patients were on monotherapy, combination therapy with at least 
two drugs, known to more effectively control BP, was the regimen most used in the study by Ikama et al. [11] The mechanisms underlying nighttime hypertension and its correlation with poor prognosis remain still not fully understood. Extrinsic and intrinsic factors including abnormal neurohormonal regulation, lack of physical activity, nutritional factors such as increased dietary sodium intake, and smoking of tobacco have been implicated for the observed blunted circadian rhythm of BP [14]. However, the two most reported mechanisms include the imbalance of nocturnal autonomic nervous system and limited sodium metabolism by the kidneys [15] [16].

Older age, female sex, diabetes, inflammation, LVH, reduced kidney function and antihypertensive therapy had emerged as the main factors associated with the non-dipping pattern. Older age has been reported to contribute to non-dipping pattern through associated vascular remodeling and insulin resistance with subsequent activation of sympathetic nervous system and clustering of multiple risk factors [17] [18] [19]. Hermida et al. [20] found that older in comparison with younger patients were more likely to have a diagnosis of microalbuminuria, CKD, obstructive sleep apnea, metabolic syndrome, anemia and/or obesity. The association of inflammation with non-dipping pattern has been already described in hypertensive patients and could reflect the status of oxidative stress and subsequent endothelial dysfunction [21] [22] [23] [24]. Female sex has been already identified as an independent predictor of blunted nighttime BP dipping and the association between nighttime BP and cardiovascular outcome has been recently reported to be stronger in women compared to men [25]. The link between female sex and non-dipping in our patients aged in average 53 years old could be the menopause, condition known to be associated with estrogen deficiency and subsequent clustering of multiple cardiovascular risk factors [25].

Non-dipping pattern has been reported to be more prevalent in hypertensive diabetics than normotensive ones [26] [27]. In this regard, one study found that a $10 \mathrm{mmHg}$ increase in nighttime SBP would be associated with a $35 \%$ increase in cardiovascular risk among diabetic populations [28]. Renal hemodynamics, blood flow distribution, and plasma volume are thought to be affected by hyperglycemia state in diabetics [27]. Another plausible mechanism underlying this abnormal circadian BP pattern in diabetics could be hyperglycemia-induced baroreflex and autonomic dysfunction [27].

Non-dipping pattern has been already reported to be associated with more severe target organ damage such as CKD and LVH [29]. CKD, defined by GFR decline and microalbuminuria, is considered an important contributor to nocturnal hypertension [30] [31]. Wang et al. [29] reported in Chinese CKD patients that $42 \%$ and $21.9 \%$ of them were non-dippers and risers, respectively. Furthermore, Afsar et al. [32] found in a study comparing patterns of dipping status in 158 hypertensive patients that 54 of them were non-dippers; among the latter, 17 patients had microalbuminuria vs. 9 patients among those with dipping pattern. Increased daily salt intake and lower potassium intake is one of the fac- 
tors underlying nocturnal hypertension and leads the kidneys to compensate high sodium intake by enhancing natriuresis during the night resulting in continuous BP elevation until kidney succeed in reducing excess sodium [33]. With reference to LVH, Verdecchia et al., [34] found that the risk of having this target organ damage was about $4 \%$ in patients with dipping pattern and increased to $15 \%$ in those with non-dipping pattern. Increased stimulation of the sympathetic nervous system and subsequent activation of the renin angiotensin system and abnormal renal sodium excretion contribute to the frequent association between the non-dipping pattern and LVH [35].

Although being on antihypertensive therapy was associated in the present study with a less likelihood of having a non-dipping pattern, the proportion of patients with this BP pattern was similar in untreated and treated subgroups. The dosing of antihypertensive drugs with the majority of patients receiving a morning dosing could partly explain the high frequency of non-dipping pattern in treated patients. Indeed, a long-acting antihypertensive drug with 24 hours duration is generally used as an initial standard treatment of hypertensive patients in order to maintain BP variability and adherence to therapy [36]. However, antihypertensive drugs used once daily are rarely effective from the morning dosing until the following morning. Thus, many hypertensives, especially non-dippers on standard treatment, still have raised BP on the morning due to the fact that the effect of antihypertensive drugs on the diurnal BP variation rely upon not only their mechanism of action but also on the time of administration, and the pharmacokinetics and pharmacodynamics of the drugs [37]. Therefore, chronotherapy, defined as administering drug while considering the optimal time in purpose to enhance drug effectiveness and tolerance, should be considered in hypertensives to reduce nocturnal hypertension and subsequent morbidity and mortality [38]. In this regard, the MAPEC study [38] showed after 5.6 years of follow up the bedtime dose achieved better overall BP control and patients taking more than one drug at bedtime showed significantly relative risk total CV events vs. those taking all drugs in the morning. The beneficial effects of the chronotherapy in hypertensive patients has been shown with renin angiotensin system inhibitors and calcium channel antagonists either alone or in combination [39]. However, this assumption has been considered inaccurate by de la Sierra et al. [1] who found no differences in relative nocturnal BP decline when comparing patients taking medication in the morning, the evening, or twice a day. Moreover, the proportion of patients receiving all or part of their medication at night was not different between dippers and non-dippers.

The interpretation of the findings of the present study should take into account of some limitations. First, its cross-design, which precludes conclusions about causal relationships, and the classification of dippers and non-dippers with a single 24-hour ABPM. Second, the small sample size did not confer much power to statistical tests to detect potential associations between variables of interest and preclude, in addition to the hospital-based characteristic of the study, the generalization of the findings to all hypertensive patients. 


\section{Conclusion}

Non-dipping that encompasses dippers and reverse dippers was the circadian BP pattern most frequently encountered in the present study. In addition to antihypertensive therapy, traditional and emerging risk factors as well as target organ damage were the main factors associated with this abnormal circadian BP pattern.

\section{Conflict of Interest}

There is no conflict of interest.

\section{Acknowledgements}

The authors would like to gratefully thank Dr Alphonse Mosolo and Wilfrid Mbombo as well as all the medical Staff of Monkole Hospital/Kinshasa, Dr Roger Kongo and Jean Takombe well as all the medical Staff of Ngaliema Clinc/ Kinshasa, Dr Albert Mvunzi Nlopo from University of Kinshasa School of Medicine, Prof Dr Pierre Akilimali from Kinshasa Public Health School and Mr Yvon Cizubu from Denk-Pharma/Kinshasa for their support. We would finally to express our gratitude to all the patients who allowed by their consent the research team to conduct the study.

\section{Author's Contribution}

TSM collected, processed data and revised the manuscript;

YL wrote the protocol, participated to data collection and analysis and revised the manuscript;

FBL participated to data analysis and wrote the manuscript; JRM participated to data analysis and revised the manuscript; AN conducted data analysis and revised the manuscript;

DKK revised the manuscript;

YS revised the manuscript;

YMN revised the manuscript;

YME revised the manuscript;

BPK revised the manuscript;

FK revised the manuscript;

DM revised the manuscript;

RMK revised the manuscript;

EVK revised the manuscript.

\section{References}

[1] de la Sierra, A., Redon, J., Banegas, J.R., et al. (2009) Prevalence and Factors Associated with Circadian Blood Pressure Patterns in Hypertensive Patients. Hypertension, 53, 466-472. https://doi.org/10.1161/HYPERTENSIONAHA.108.124008

[2] Fagard, R.H., Celis, H., Thijs, L., et al. (2008) Daytime and Nighttime Blood Pressure as Predictors of Death and Cause-Specific Cardiovascular Events in Hypertension. Hypertension, 51, 55-61. 
https://doi.org/10.1161/HYPERTENSIONAHA.107.100727

[3] M’Buyamba-Kabangu, J.R., Fagard, R., Staessen, J., Lijnen, P. and Amery, A. (1987) Correlates of Blood Pressure in Rural and Urban Zaire. Journal of Hypertension, 5 , 371-375. https://doi.org/10.1097/00004872-198706000-00018

[4] Katchunga, P.B., M’buyamba-Kayamba, J.R., Masumbuko, B.E., et al. (2011) Hypertension in the Adult Congolese Population of Southern Kivu: Results of the Vitaraa Study. La Presse Médicale, 40, e315-e323. https://doi.org/10.1016/j.lpm.2010.10.036

[5] Kianu, P.B., Mpembele, M.E., Kintoki, E.V., et al. (2015) Rates of Hypertension Prevalence, Awareness, Treatment and Control in Congolese South West Port City. The Influence of Gender According to Age Groups. Global Journal of Medical Research, 1, 1-8

[6] Lepira, F.B., M’Buyamba-Kabangu, J.R., Kayembe, K.P. and Nseka, M.N. (2006) Clinical Correlates of Left Ventricular Hypertrophy in Black Patients with Arterial Hypertension. Cardiovascular Journal of South Africa, 17, 7-11.

[7] Mpembe, B.C., Lepira, F.B., Mbutiwi, F.I., et al. (2015) Left Ventricular Structure, Geometry and Systolic Function among Hypertensive Black Patients with Reduced Kidney Function. World Journal of Cardiovascular Diseases, 5, 287-295. https://doi.org/10.4236/wjcd.2015.510032

[8] M'Buyamba-Kabangu, J.R., Biswika, R.T., Thijs, L., et al. (2009) In-Hospital Mortality among Black Patients Admitted for Hypertension-Related Disorders in Mbuji-Mayi, Congo. American Journal of Hypertension, 22, 643-648. https://doi.org/10.1038/ajh.2009.47

[9] Kika, T.M., Lepira, F.B., Kayembe, P.K., et al. (2016) Uncontrolled Hypertension among Patients Managed in Primary Healthcare Facilities in Kinshasa, Democratic Republic of the Congo. Cardiovascular Journal of South Africa, 27, 361-366. https://doi.org/10.5830/CVJA-2016-036

[10] Pickering, T.G. and Kario, K. (2001) Nocturnal Non-Dipping: What Does It Augur? Current Opinion in Nephrology and Hypertension, 10, 611-616. https://doi.org/10.1097/00041552-200109000-00010

[11] Ikama, S.M., Nsitou, B.M., Makani, J., et al. (2015) Practice of Ambulatory Blood Pressure Monitoring in Brazzaville, Congo. Preliminary Results. Pan African Medical Journal, 20, 353. (In French)

[12] Uys, A.S., Malan, L., van Rooyen, J.M., et al. (2009) Nocturnal Blood Pressure, 3-methoxy-4-hydroxyphenylglycol and Carotid Intima-Media Thickness: The SABPA Study. Heart, Lung and Circulation, 22, 917-923.

[13] Ivy, H., Tam, J., Matthew, J., et al. (2015) Ambulatory Blood Pressure Monitoring to Assess the White-Coat Effect in an Elderly East African Population. The Journal of Clinical Hypertension, 17, 389-394. (In Greenwich) https://doi.org/10.1111/jch.12501

[14] Kanbay, M., Turgut, F., Uyar, M.E., et al. (2008) Causes and Mechanisms of Nondipping Hypertension. Clinical and Experimental Hypertension, 30, 585-597. https://doi.org/10.1080/10641960802251974

[15] Kristanto, A., Adiwinata, R., Suminto, S., et al. (2016) Noctunal Hypertension: Neglected Issue in Comprehensive Hypertension Management. Journal of Internal Medicine, 48, I76-I82.

[16] Bankir, L., Bochud, M., Maillard, M., et al. (2008) Nighttime Blood Pressure and Nocturnal Dipping Are Associated with Daytime Urinary Sodium Excretion in African Subjects. Hypertension, 51, 891-898. 
https://doi.org/10.1161/HYPERTENSIONAHA.107.105510

[17] Polónia, J., Madede, T., Silva, J.A., et al. (2014) Ambulatory Blood Pressure Monitoring Profile in Urban African Black and European White Untreated Hypertensive Patients Matched for Age and Sex. Blood Pressure Monitoring, 19, 192-198. https://doi.org/10.1097/MBP.0000000000000046

[18] Ramos, R., Marrugat, J., Basagana, X., et al. (2004) The Role of Age in Cardiovascular Risk Factor Clustering in Non-Diabetic Population Free of Coronary Heart Disease. European Journal of Epidemiology, 19, 299-304. https://doi.org/10.1023/B:EJEP.0000024697.55346.c2

[19] Plante, G.E. (2003) Impact of Aging on the Body's Vascular System. Metabolism, 52, 31-35.

[20] Hermida, R.C., Ayala, D.E., Crespo, J.J., et al. (2013) Influence of Age and Hypertension Treatment-Time on Ambulatory Blood Pressure in Hypertensive Patients. Chronobiology International, 30, 176-191. https://doi.org/10.3109/07420528.2012.701131

[21] Kruger, R., Schutte, R., Huisman, H.W., et al. (2012) Associations between Reactive Oxygen Species, Blood Pressure and Arterial Stiffness in Black South Africans: The SABPA Study. Journal of Human Hypertension, 26, 91-97. https://doi.org/10.1038/jhh.2010.134

[22] Ahbap, E., Sakaci, T., Kara, E., et al. (2016) Serum Uric Acid Levels and Inflammatory Markers with Respect to Dipping Status: A Retrospective Analysis of Hypertensive Patients with or without Chronic Kidney Disease. Clinical and Experimental Hypertension, 38, 555-563. https://doi.org/10.3109/10641963.2016.1174251

[23] Ozcan, F., Turak, O., Durak, A., et al. (2013) Red Cell Distribution Width and Inflammation in Patients with Non-Dipper Hypertension. Blood Press, 22, 80-85. https://doi.org/10.3109/08037051.2012.707336

[24] Tsioufis, C., Syrseloudis, D., Dimitriadis, K., et al. (2008) Disturbed Circadian Blood Pressure Rhythm and C-Reactive Protein in Essential Hypertension. Journal of Human Hypertension, 22, 501-508. https://doi.org/10.1038/jhh.2008.20

[25] Sherwood, A., Bower, J.K., Routledge, F.S., et al. (2012) Nighttime Blood Pressure Dipping in Postmenopausal Women with Coronary Artery Disease. American Journal of Hypertension, 25, 1077-1082. https://doi.org/10.1038/ajh.2012.95

[26] Kengne, A.P., Libend, C.N., Dzudie, A., et al. (2014) An Assessment of Discriminatory Power of Office Blood Pressure Measurements in Predicting Optimal Ambulatory Blood Pressure Control in People with Type 2 Diabetes. Pan African Medical Journal, 19, 231. https://doi.org/10.11604/pamj.2014.19.231.2608

[27] Cuspidi, C., Meani, S., Fonati, L., et al. (2006) Short-Term Reproducibility of a Non-Dipping Pattern in Type 2 Diabetic Hypertensive Patients. Journal of Hypertension, 24, 647-653. https://doi.org/10.1097/01.hjh.0000217846.65089.19

[28] Atabek, M.E., Akyurek, N., Eklioglu, B.S., et al. (2014) Impaired Systolic Blood Dipping and Nocturnal Hypertension: An Independent Predictor of Carotid Intima-Media Thickness in Type 1 Diabetic Patients. Journal of Diabetes and its Complications, 2014, 51-55.

[29] Wang, C., Ye, Y., Liu, C., et al. (2017) Evening versus Morning Dosing Regimen Drug Therapy for Chronic Kidney Disease Patients with Hypertension in Blood Pressure Patterns: A Systematic Review and Meta-Analysis. Internal Medicine Journal. https://doi.org/10.1111/imj.13490

[30] Isobe, S., Ohashi, N., Fujikura, T., et al. (2014) Disturbed Circadian Rhythm of the 
Intrarenal Renin-Angiotensin-Relevant to Nocturnal Hypertension and Renal Damage. Clinical and Experimental Nephrology, 19, 231-239. https://doi.org/10.1007/s10157-014-0973-2

[31] Schutte, R., Schutte, A.E., Huisman, H.W., et al. (2011) Arterial Stiffness, Ambulatory Blood Pressure and Low-Grade Albuminuria in Non-Diabetic African and Caucasian Men: The Sabpa Study. Hypertension Research, 34, 862-868. https://doi.org/10.1038/hr.2011.45

[32] Afsar, B. and Elsurer, R. (2010) Urinary Albumin Excretion among Non-Dipper Hypertensive Patients Is Closely Related with the Pattern of Non-Dipping. Journal of the American Society of Hypertension, 4, 196-202.

[33] Kimura, G., Dohi, Y. and Fukuda, M. (2010) Salt Sensitivity and Circadian Rhythm of Blood Pressure: The Keys to Connect CKD with Cardiovascular Events. Hypertension Research, 33, 515-520. https://doi.org/10.1038/hr.2010.47

[34] Verdecchia, P., Schillaci, G., Guerreri, M., et al. (1990) Circadian Blood Pressure Changes and Left Venttiruclar Hypertrophy in Essential Hypertension. Circulation, 81, 528-536. https://doi.org/10.1161/01.CIR.81.2.528

[35] Malan, L., Hamer, M., Frasure-Smith, N., et al. (2015) Cohort Profile: Sympathetic Activity and Ambulatory Blood Pressure in Africans (SABPA) Prospective Cohort Study. International Journal of Epidemiology, 1814-1822. https://doi.org/10.1093/ije/dyu199

[36] Flack, J.M. and Nasser, S.A. (2011) Benefits of Once-Daily Therapies in the Treatment of Hypertension. Vascular Health and Risk Management, 7, 777-787. https://doi.org/10.2147/VHRM.S17207

[37] Kario, K. (2005) Morning Hypertension: A Pitfall of Current Hypertensive Management. Clinic, 18, 21.

[38] Fujimura, A. (2013) Chronotherapy-Present and Future. Nihon Rinsho, 71, 2097-2101.

[39] Hermida, R.C., Diana, E.A., Artemio, M., et al. (2010) Influence of Circadian Time of Hypertension Treatment Cardiovascular Risk: Results of the MAPEC Study. Chronobiology International, 27, 1629-1651. https://doi.org/10.3109/07420528.2010.510230 